\title{
Widespread cranial nerve palsies while on cyclophosphamide therapy: a very rare manifestation of Wegener's granulomatosis (granulomatosis with polyangitis)
}

\author{
Syed Viqar Ahmed, Sumit Chandra
}

Acute Medicine, Stepping Hill Hospital, Stockport, UK

Correspondence to Dr Syed Viqar Ahmed, syedviqarahmed@hotmail.com

\section{BACKGROUND}

Wegener's granulomatosis (granulomatosis with polyangitis) is a rare autoimmune disease causing necrotising vasculitis of small blood vessels, mainly affecting the upper (90\%) and lower (60\%) respiratory tract tissues and kidneys $(75 \%)$. Central nervous system (CNS) involvement is limited to $2-8 \%$ of cases while cranial nerve involvement is seen in only $1 \%$ of cases. Most cases are due to the granulomatous involvement of meninges (pachymeningitis), resulting in cranial nerve palsies. Very rarely, CNS lesions are caused by vasculitis of small vessels.

We report a case of a man who, while being treated with cyclophosphamide, presented with an acute flare of the disease affecting all the cranial nerves except the olfactory, trigeminal and facial nerves. Extensive investigations failed to show any meningeal involvement, supporting the view of extensive small vessel vasculitis. It is extremely rare to have such an extensive cranial nerve involvement with no evidence of meningeal involvement.

Immunosuppressive therapy with cyclophosphamide is considered to be the mainstay of the treatment (along with steroids) with complete remission seen in a large majority of cases. However, in this case, he was refractory to cyclophosphamide and also failed to respond to alternative therapy with rituximab (a monoclonal antibody that binds to CD20). After being on a high-dose steroid therapy for nearly a year, he successfully responded to subcutaneous methotrexate therapy, thus enabling the steroid dose to be reduced significantly.

\section{CASE PRESENTATION}

A 59-year-old Caucasian man with no significant medical history was diagnosed with Wegener's granulomatosis (granulomatosis with polyangitis) when he presented with deafness, epistaxis, haemoptysis, cavitating lung lesion on chest X-ray, high inflammatory markers, a very positive c-ANCA (c-antineutrophil cytoplasmic antibody) and antiproteinase three antibodies but no renal involvement or joint symptoms. He responded very well to cyclophosphamide infusions and methylprednisolone with steady improvement of his inflammatory markers and symptoms. Thereafter, his steroid dose was tapered off while he was continued on cyclophosphamide with a plan to change to methotrexate after 6 months.

While undergoing cyclophosphamide therapy, he was readmitted as an emergency with severe headache, photophobia, vomiting and visual symptoms.
On examination, his visual acuity was 6/9 right and 6/6 left (corrected with a pinhole); eye movements revealed reduced adduction, abduction and elevation of the right eye only. The pupils were small and symmetrical with mild right-sided ptosis and fundoscopy normal. His MRI brain and orbital scan with contrast did not show any significant abnormality and lumbar puncture was normal. $\mathrm{He}$ was again treated with high-dose intravenous steroids and cyclophosphamide with rapid recovery within days.

While still on cyclosphosphamide and a tapering dose of steroids, he was again admitted with severe headache, visual symptoms, deafness and difficulty in swallowing. On examination, he had total akinesia of the right eye, with several right cranial nerve palsiessecond (optic) nerve with impaired colour vision (visual acuity unaffected), partial third nerve, fourth (trochlear) nerve, sixth (abducent) nerve, eighth (vestibulocochlear) nerve, ninth(glossopharyngeal) nerve, 10th (vagus) nerve, 11th (accessory) nerve and 12th (hypoglossal) nerve (video 1).

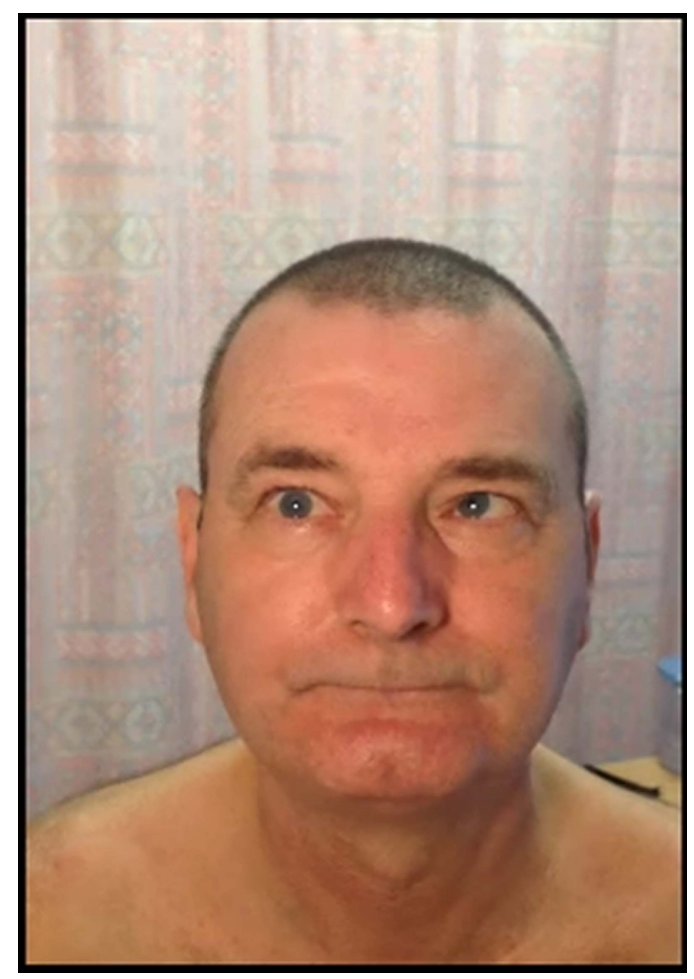

Video 1 Multiple cranial nerve palsies in granulomatosis with polyangitis. 


\section{INVESTIGATIONS}

Inflammatory markers (erythrocyte sedimentation rate/C reactive protein) were raised (also during flare ups), which improved with immunosuppressive treatment. MR brain scan with gadolinium was normal with no evidence of basal meningitis. MR brain scan with gadolinium and MR angiography was normal. Lumbar puncture was twice normal.

\section{DIFFERENTIAL DIAGNOSIS}

There was no evidence of infection.

\section{TREATMENT}

After being diagnosed in June 2011, he remained on high-dose steroids along with cyclophosphamide. Any attempt to reduce steroids while on cyclophosphamide immediately resulted in the recurrence of symptoms. After receiving 11 infusions of cyclophosphamide, he was switched to oral methotrexate for 3 months, but any attempts to reduce the steroids immediately resulted in a flare-up of symptoms. On the advice of a national expert, methotrexate was replaced with mycophenolate mofetil. However, the patient developed abdominal symptoms with higher doses. It was then replaced by rituximab but had to be discontinued due to the rapid flare-up of symptoms after two doses. At this stage, it was decided to change to a subcutaneous form of methotrexate ( $25 \mathrm{mg}$ subcutaneous weekly) in order to increase its bioavailability. He responded very well to this regime and is now on a reducing dose of prednisolone less than $10 \mathrm{mg} /$ day with no flareup of symptoms.

\section{OUTCOME AND FOLLOW-UP}

His headaches have not been problematic and his double vision has improved, though not completely. His visual acuity with glasses has been 6/6 right eye and 6/5 left eye while his eye movements reveal a slight reduction in abduction of the right eye. His fundoscopy is normal and reveals no facial weakness or bulbar problems. Palatal movements appeared midline with no tongue deviation on protrusion. Cavitating lung lesion showed complete resolution.

In view of dyspepsia and transient rectal bleeding, gastroscopy was performed that showed oesophageal candida and nonspecific gastritis (Helicobacter pylori positive), which was treated appropriately. This was followed by colonoscopy that showed an incidental fibroepithelial polyp only.

He remains under review in the follow-up clinics: rheumatology, neurology and ophthalmology.

\section{DISCUSSION}

Wegener's granulomatosis (granulomatosis with polyangitis) is a small vessel disease that causes autoimmune necrotising vasculitis. It commonly affects the kidneys and upper and lower respiratory tract tissues in variable combination (though it can affect almost every organ of the body). It is typically associated with c-ANCA and antiproteinase three antibodies. The granulomatous involvement of the nasal or paranasal tissues may spread to the neighbouring meninges resulting in cranial nerve palsies. However, such meningeal involvement is rare and is seen in only $1 \%$ of cases $^{1-3}$ (CNS involvement is around 2$8 \%)$. It can be confirmed by imaging, such as an MRI of the brain. Early detection and treatment can help prevent long-term complications. Very rarely, such lesions can be caused by vasculitis of the small vessels, which is very difficult to diagnose, even with angiography.
Unexpectedly, in our case, MRI brain (twice) and orbital scan with contrast was normal. In view of the high clinical possibility of basal meningitic process secondary to Wegener's granulomatosis, an MRI of the brain with gadolinium was performed, but it was normal with no leptomeningeal enhancement. Therefore, it is fair to assume that the pathological process is at the level of small vessel vasculitis resulting in multiple cranial nerve palsies.

There are no case reports in the English literature suggesting such an extensive cranial nerve involvement due to vasculitis rather than pachymeningitis in Wegener's granulomatosis. A combination of steroids with immunosuppressive therapy helped to control the symptoms and lowered the inflammatory markers, but any attempt to reduce the steroids immediately led to a flare-up of the symptoms. The poor response to cyclophosphamide therapy is well known (called refractory WG), and usually, such patients respond to rituximab. However, our patient failed to respond to such therapy. Azathiaprine has been successfully used in such nonresponders, ${ }^{4}$ but it was not considered in our case. Though initially the disease failed to respond to oral methotrexate, it responded very well to subcutaneous methotrexate, thus enabling the high-dose steroids to be reduced successfully.

Cyclophosphamide is particularly associated with cancer of the bladder and other organs. Prolonged immunosuppressive therapy may increase the risk of opportunistic infections such as Pneumocystis (carinii) jiroveci.

\section{Learning points}

- Patients not responding to cyclophosphamide therapy present a real management challenge for the specialists.

- Morbidity in Wegener's granulomatosis (granulomatosis with polyangitis) is related to its treatment.

- Long-term cyclophosphamide use is associated with a significant risk of cancer of the bladder. Similarly, overall cancer risk with cyclophosphamide is significantly high and any red flag sign should prompt early referral for investigations.

- Long-term immunosuppressive therapy in Wegener's granulomatosis (granulomatosis with polyangitis) increases the risk for opportunistic infections, such as Pneumocystis (carinii) jiroveci pneumonia, and prophylactic treatment may be required to prevent complications.

Acknowledgements The authors are grateful to Syed Hamza Ahmed, for proof-reading and finalising the video clip.

Contributors SVA and SC contributed to developing the video clip, literature search and proof-reading.

Competing interests None.

Patient consent Obtained.

Provenance and peer review Not commissioned; externally peer reviewed.

\section{REFERENCES}

1 Hoffman GS, Kerr GS, Leavitt RY, et al. Wegener's granulomatosis: an analysis of 158 patients. Ann Intern Med 1992;116:488-98.

2 Drachman D. Neurological complications of Wegener's granulomatosis. Arch Neurol 1963;8:145-55.

3 Nishino H, Rubino FA, DeRemee RA, et al. Neurological involvement in Wegener's granulomatosis: an analysis of 324 consecutive patients at the Mayo Clinic. Ann Neurol 1993;33:4-9.

4 Aries PM, Hellmich B, Voswinkel J, et al. Efficacy of rituximab in Wegener's granulomatosis with refractory granulomatous manifestations. Ann Rheum Dis 2006:65:853-8. 
Copyright 2013 BMJ Publishing Group. All rights reserved. For permission to reuse any of this content visit http://group.bmj.com/group/rights-licensing/permissions.

BMJ Case Report Fellows may re-use this article for personal use and teaching without any further permission.

Become a Fellow of BMJ Case Reports today and you can:

- Submit as many cases as you like

- Enjoy fast sympathetic peer review and rapid publication of accepted articles

- Access all the published articles

- Re-use any of the published material for personal use and teaching without further permission

For information on Institutional Fellowships contact consortiasales@bmjgroup.com

Visit casereports.bmj.com for more articles like this and to become a Fellow 